\title{
Is Fragility Fracture a Strong Risk Factor for a Cardiovascular Event in Rheumatoid Arthritis? The Challenge of Dealing with Multiple Comorbidities
}

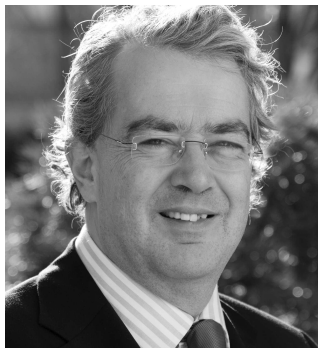

Multiple comorbidities are among the most important challenges today because comorbidity is age-related and the population is aging ${ }^{1}$. In patients with rheumatoid arthritis (RA), the risk of both fragility fractures (FF) and cardiovascular (CV) manifestations is elevated $2,3,4,5$, but are these comorbidities separate processes, or are they interrelated? If these events (partly) share a common pathogenesis, an FF is not only a strong risk factor for a subsequent fracture ${ }^{6}$, but also for a $\mathrm{CV}$ event. As a consequence, it might be useful to determine the $\mathrm{CV}$ risk after a recent fracture.

The study by Ni Mhuircheartaigh, et $a l^{7}$ brings up exciting data that show that CV risk, both of myocardial infarction (MI) and heart failure, is elevated after an FF in patients with RA. In an observational study in Olmsted County (USA) from 1995 to 2007, 1171 patients with incident RA and 1171 controls were included. At baseline, the patients had hypertension, obesity, and dyslipidemia more often, but RA patients with a previous event were excluded. During followup, 406 and $346 \mathrm{FF}$ were observed, and 286 and 225 $\mathrm{CV}$ events, respectively. After adjustments, the overall CV risk was increased for patients with RA following any FF (HR 1.81, 95\% CI 1.38-2.37), and also after a major fracture (HR $1.80,95 \%$ CI $1.35-2.40$ ). Because FF predominantly occur in the elderly, the $80 \%$ increase in relative risk indicates a substantial increase in absolute risk of $\mathrm{CV}$ events. In the RA patients without an FF fracture, no statistically significant difference was found (HR 1.18, 95\% CI 0.85-1.63).

What is the explanation for the elevated CV risk in patients with RA after a recent FF? Some traditional risk factors are relevant for both osteoporotic fractures and CV events: aging, postmenopausal status, and smoking. Recently it has been shown that diabetes mellitus is not only a risk factor for CV events, but it also impairs bone strength and increases the incidence of fractures ${ }^{8}$. Systemic inflammation, a sedentary lifestyle, and frailty are probably among the most important risk factors for both osteoporotic fractures and $\mathrm{CV}$ events. Earlier, it was shown that elevated C-reactive protein levels are associated with an increase in both types of events $^{9,10}$, probably related to increased levels of inflammatory cytokines as tumor necrosis factor- $\alpha$ (TNF- $\alpha$ ), interleukin 1 (IL-1), and IL-6.

Theoretically, smoking, diabetes, and systemic inflammation are among the modifiable risk factors for both FF and $\mathrm{CV}$ events. This opens up the possibility that with modern antirheumatic treatment in a treat-to-target design aiming at remission, systemic inflammation is more under control, with subsequent lowering in event rate. Indeed, we have shown that with effective treatment of RA with infliximab or adalimumab, the usually occurring generalized bone loss, measured by bone mineral density (BMD) at the spine and hips, can be arrested ${ }^{11,12}$. Very recent data suggest that the use of TNF inhibitors reduces CV risk in $\mathrm{RA}^{13}$.

A striking point is that in the control group of RA patients without a recent FF, no statistically significant increase in $\mathrm{CV}$ events was found, which could be related to a type 2 error that masks an only slightly elevated $\mathrm{CV}$ event rate in RA patients with mild disease, while it could probably be documented in a study with a larger number of patients. In line with that, in a recent metaanalysis, it was shown in the general population that in individuals with BMD in the osteoporotic range, the risk of atherosclerotic vascular abnormalities was 2 to 3 times higher ${ }^{14}$.

Another question is whether fracture risk is elevated after a recent $\mathrm{CV}$ event. In an earlier systematic review, that question could not be answered properly, because of the heterogeneity of $\mathrm{CV}$ events that were enrolled: patients with MI, stroke, and aortic calcification ${ }^{15}$. However, hip fracture risk was elevated after heart failure and stroke ${ }^{16}$, and in postmenopausal women with a recent $\mathrm{MI}^{17}$.

One of the limitations of the study is that it was conducted in white women (93\%). Thus, extrapolation to men and women from other continents or another genetic background or race is not possible ${ }^{18}$. The authors mention that the use of calcium supplementation might be a bias, because calcium (and vitamin D) is often prescribed after an FF and because calcium supplementation and increased $\mathrm{CV}$ risk might be

See Fragility fractures and CV events in RA, page 558

Personal non-commercial use only. The Journal of Rheumatology Copyright @ 2017 . All rights reserved. 
associated, but that is still a matter of debate. Another issue is whether the relationship can also be found in recent cohorts of RA, with modern treatment aiming at remission. Probably the most important limitation is that no data are presented that show the relationship with (cumulative) disease activity, functional capacity, and/or radiological damage, and the risk of $\mathrm{CV}$ events. On average, the risk of a CV event is $80 \%$ higher in patients with RA, but likely even higher in RA patients with severe or less controllable disease, and lower in patients in clinical remission.

What is the next step on the research agenda? First, the data from Olmsted should be confirmed in other RA cohorts, preferably from other continents and including also non-white patients. If confirmed, we will have better insight into the additional risk for RA patients for $\mathrm{CV}$ events after an FF, preferably with data for subcategories of RA patients with severe or mild RA. Interestingly, it was recently mentioned by the European League Against Rheumatism that comorbidities are often suboptimally prevented, screened, and managed ${ }^{19}$. Nevertheless, in an aging population, our patients expect from us as rheumatologists: optimal care and treatment not only for their rheumatic disease, but also for their comorbidities.

WILLEM F. LEMS, $\mathrm{MD}, \mathrm{PhD}$,

Rheumatologist,

Department of Rheumatology,

Amsterdam Rheumatology and

Immunology Center,

VU University Medical Center, Amsterdam, the Netherlands.

Address correspondence to Prof. W.F. Lems, Department of Rheumatology, Amsterdam Rheumatology and Immunology Center, VU University Medical Center, 3A 64 Postbox 7057, 1007 MB, Amsterdam, the Netherlands.E-mail:.wf.lems@vumc.nl

\section{REFERENCES}

1. Barnett K, Mercer SW, Norbury M, Watt G, Wyke S, Guthrie B. Epidemiology of multimorbidity and implications for health care, research and medical education: a cross-sectional study. Lancet 2012;7:380:37-43.

2. Ørstavik RE, Haugeberg G, Mowinckel P, Høiseth A, Uhlig T, Falch JA, et al. Vertebral deformities in RA: a comparison with population-based controls. Arch Intern Med 2004;164:420-5.

3. van Staa TP, Geusens P, Bijlsma JW, Leufkens HG, Cooper C. Clinical assessment of the long-term risk of fracture in patients with RA. Arthritis Rheum 2006;54:3104-12.

4. Peters MJ, van Halm VP, Voskuyl AE, Smulders YM, Boers M, Lems WF, et al. Does RA equal diabetes mellitus as an independent risk factor for cardiovascular diseases? A prospective study. Arthritis rheum 2009;15:1571-9.

5. Symmons DP, Gabriel SE. Epidemiology of CVD in rheumatic disease, with a focus on RA and SLE. Nat Rev Rheumatol 2011;31:399-408.

6. Klotzbuecher CM, Ross PD, Landsman PB, Abbott TA 3rd, Berger M. Patients with prior fractures have an increased risk of future fractures: a summary of the literature and statistical synthesis. J Bone Miner Res 2000;15:721-39.

7. Ni Mhuircheartaigh O, Crowson CS, Gabriel SE, Roger VL, Melton LJ 3rd, Amin S. Fragility fractures are associated with an increased risk for cardiovascular events in RA. J Rheumatol 2017;44:558-64.

8. Napoli N, Chandran M, Pierroz DD, Abrahamsen B, Schwartz AV, Ferrari SL, et al. Mechanisms of diabetes-mellitus induced bone fragility. Nat Rev Endocrinol 2016 Sep 23 (E-pub ahead of print).

9. Schett G, Kiechl S, Weger S, Pederiva A, Mayr A, Petrangeli M, et al. High sensitivity $\mathrm{C}$-reactive protein and risk of nontraumatic fractures in the Bruneck study. Arch Int Med 2006;166:2495-501.

10. Emerging Risk Factors Collaboration; Kaptoge S, Di Angelantonio E, Pennells L, Wood AM, White IR, et al. C-reactive protein, fibrinogen, and cardiovascular disease prediction. N Engl J Med 2012;367:1310-20

11. Vis M, Havaardsholm EA, Haugeberg G, Uhlig T, Voskuyl AE, van de Stadt RJ, et al. Evaluation of bone mineral density (BMD), bone metabolism, osteoprotegerin and receptor activator of the NFkappaB ligand serum levels during treatment with infliximab in patients with RA. Ann Rheum Dis 2006;65:1495-9.

12. Krieckaert CL, Nurmohamed MT, Wolbink G, Lems WF. Changes in bone mineral density during long-term treatment with adalimumab in RA-patients: a cohort study. Rheumatology 2013;52:547-53.

13. Low AS, Symmons DP, Lunt M, Mercer LK, Gale CP, Watson KD, et al. Relationship between exposure to TNF inhibitor therapy and severity of myocardial infarction in RA. Ann Rheum Dis 2017 Jan 10 (E-pub ahead of print).

14. Ye C, Xu M, Wang S, Jiang S, Chen X, Zhou X, et al. Decreased bone mineral density is an independent predictor for the development of atherosclerosis: a systematic review and meta-analysis. PLoS One 2016;11:e0154740.

15. den Uyl D, Nurmohamed MT, van Tuyl LH, Raterman HG, Lems WF. (Sub)clinical cardiovascular disease is associated with increased bone loss and fracture risk; a systematic review of the association between cardiovascular disease and osteoporosis. Arthritis Res Ther 2011;17:13(1)R5.

16. Sennerby U, Melhus H, Gedeborg R, Byberg L, Garmo H, Ahlbom A, et al. Cardiovascular disease and risk of hip fracture. JAMA 2009;302:1666-73.

17. Gerber Y, Melton LJ 3rd, Weston SA, Roger VL. Association between myocardial infarction and fractures: an emerging phenomenon. Circulation 2011;124:297-303.

18. Yusuf S, Phil D, Wittes J. Interpreting geographic variations in results of randomized, controlled trials. N Engl J Med 2016;23:2263-71.

19. Baillet A, Gossec L, Carmona L, Wit MD, van Eijk-Hustings Y, Bertheussen $\mathrm{H}$, et al. Points to consider for reporting, screening and preventing selected comorbidities in chronic inflammatory rheumatic diseases in daily practice: a EULAR initiative. Ann Rheum Dis 2016;75:965-73.

J Rheumatol 2017;44:545-6; doi:10.3899/jrheum.170202 